\title{
Caracterización de saberes locales alrededor de la producción de Chicha en el Valle de Tenza, Boyacá (Colombia) ${ }^{2}$
}

\author{
Characterization of local knowledge about the production of \\ Chicha in Valle de Tenza, Boyacá (Colombia)
}

\begin{abstract}
Resumen
Esta investigación fue desarrollada con el objetivo de caracterizar y reconocer los saberes locales alrededor de la producción de Chicha. Se realizó en tres municipios del Valle de Tenza en el Departamento de Boyacá (Colombia): Sutatenza, Guateque y Macanal, por medio de la metodología cualitativa con enfoque etnográfico. En consecuencia, se llevó a cabo una observación de aspectos relacionados con la producción de Chicha y entrevistas semiestructuradas con preguntas abiertas a nueve habitantes de la zona, quienes conocían su elaboración. Posteriormente, se seleccionó y analizó la información obtenida para cumplir con el objetivo del proyecto. Este artículo inicia con una aproximación conceptual a los términos principales. Enseguida se realiza una descripción y caracterización metodológica. Luego, se comentan los resultados y por último se presentan las conclusiones del trabajo.
\end{abstract}

Palabras clave: saberes locales, Chicha, Valle de Tenza, construcción social del conocimiento.

\begin{abstract}
This research was development in order to characterize and recognize local knowledge about the production of Chicha. It was developed in three towns in the Valle de Tenza in the Department of Boyacá (Colombia): Sutatenza, Guateque and Macanal, through qualitative ethnographic methodology approach. Consequently, it was developed an observation of aspects related to the production of Chich a and semi-structured interviews with nine peasants from the mentioned towns, who knew the production process. Later, it was selected and analyzed the obtained information to reach the project objective.

This article begins by showing a conceptual approach to the main concepts, once a description and characterization methodology is made. Then, the results are discussed and finally the conclusions are presented.
\end{abstract}

Keywords: local knowledge, Chicha, Valle de Tenza, knowledge's social construction.

\section{Recibido: 7 de octubre de 2015, evaluado: 18 de octubre de 2015, aprobado: 7 de noviembre de 2015}

1 Licenciada en Biología con énfasis en biotecnología de la Universidad Pedagógica Nacional. Coordinadora de Pre-Icfes y profesora de Biología PreIcfes, Pontificia Universidad Javeriana. Correo electrónico: alejita-nani@hotmail.com

2 Artículo resultado de la monografía de grado de la Licenciatura en Biología, Universidad Pedagógica Nacional-2015. 


\section{Introducción}

Debido a que las actuales dinámicas sociales, educativas, culturales y tecnológicas han fomentado la pérdida de los saberes locales, se hace necesario indagar por los mismos en aras de recuperarlos, por lo cual el primer paso es caracterizarlos y describirlos. En particular, los cambios socioculturales se reflejan en la escuela evidenciando transformaciones en las dinámicas tradicionales de las comunidades campesinas y el reemplazo de los saberes locales por el conocimiento disciplinar, que invisibilizan el saber del otro. Lo anterior también se debe a la naturaleza oral de los saberes locales, a su forma de enseñanza (que depende de contextos particulares) y a las relaciones necesarias que deben existir entre generaciones para que sigan teniendo importancia y continuidad en una comunidad.

La importancia de los saberes locales radica en que estos permiten constatar la forma en la que se ha construido socialmente el conocimiento, con lo que se evidencia su valor social, cultural y educativo de tipo informal. Por otro lado, el reconocimiento de estos saberes es relevante porque permite entender, determinar y describir la forma en que las comunidades han construido socialmente el conocimiento en torno a la producción de Chicha. Esto es fundamental para identificar las prácticas educativas informales y otras relaciones socioculturales que se han llevado a cabo por varias generaciones en la región. Asimismo, su caracterización y reconocimiento fomenta la recuperación de prácticas tradicionales importantes en la configuración de la identidad campesina del Valle de Tenza.

Con lo anterior, la categorización de los saberes locales de los habitantes del Valle de Tenza con respecto a la producción de Chicha produjo seis categorías de análisis: 1) aspectos sociolingüísticos; 2) métodos de elaboración; 3) consumo de la Chicha; 4) prácticas socioculturales; 5) usos socioculturales; y 6), creencias de la comunidad en la elaboración de la bebida. Las categorías evidenciaron particularidades correspondientes a la zona de estudio y sus relaciones históricas, geográficas, sociales y culturales. En general, se encontró que el saber local actual es una hibridación de saberes que surgió primero con los indígenas, se modificó con la colonización española, enfrentó cambios generados por los procesos de modernización e industrialización, después se nutrió con algunos saberes científicos; y ahora afronta nuevos cambios debido a las inmigraciones y la integración de prácticas modernas.

\section{Revisión conceptual}

\section{Conceptualizando los saberes locales}

Es importante entender que cuando se habla de "saber local" se hace referencia a "toda una gama de conocimientos de carácter empírico transmitidos oralmente que son propios de las formas no industriales de apropiación de la naturaleza" (Toledo, 2005, p. 5), y que pertenecen a una comunidad particular, sobre situaciones o prácticas específicas. De igual manera, los saberes locales

[...] representan un conocimiento que, aunque no codificado, resuelve los problemas de la vida práctica de los miembros de la unidad social que lo ha construido y que tiene la ventaja de poseer información que otros grupos sociales desconocen y la ciencia no tiene acceso por sus medios. (Torres, 2011, p. 15)

Esto hace que el saber local sea una construcción colectiva particular, reflejo de las relaciones con el territorio, con los otros miembros de la comunidad y con los seres vivos a través de múltiples experiencias, en donde el ensayo-error permite diversos aprendizajes.

Los saberes locales son un “(...) cúmulo social de cogniciones apropiadas y relativamente compartidas (...) transmitidos de generación en generación, por medio de la tradición oral" (Gómez \& Gómez, citado por Landini, 2010, p. 22). En consecuencia, Núñez (citado por Landini, 2010) sostiene que los saberes locales son todos aquellos 
conocimientos sobre suelos, clima, gestión de cultivos y otros aspectos de la actividad productiva, desarrollados por la comunidad a lo largo del tiempo por medio de la experimentación y la observación minuciosa y atenta de la naturaleza.

\section{Una bebida ancestral: recuento histórico y sociocultural de la Chicha}

Esta investigación se centra en la producción de Chicha debido a que esta bebida es importante para la comunidad por su relevancia social y cultural, así como por su historicidad y antigüedad en la región.

La Chicha es una bebida fermentada tradicional, no destilada, que actualmente se elabora a base de maíz, agua y miel de caña, pero existen muchas variantes. Se realiza en países como Perú, Ecuador, Venezuela, Panamá, Chile y Bolivia, entre otros, y cada lugar tiene una manera particular de prepararla, agregando nuevos y diversos ingredientes a la misma. Actualmente existen varios tipos de Chicha: a base de maíz, avena, arroz, arracacha; de los siete granos (haba, lenteja, garbanzo, alverja, cebada, trigo y maíz); a partir de frutas (de piña, manzana); de maní; y de quinua, entre otras. Sin embargo, para efectos de esta investigación, se analiza únicamente el proceso de producción de la Chicha de maíz en tres municipios del Valle de Tenza, Boyacá (Colombia).

Según Steinkraus (1995), el contenido alcohólico de la Chicha varía entre 2 y 12 \% (v/v). Los efectos principales de consumirla en exceso son los mismos de cualquier bebida alcohólica: a nivel fisiológico causa intoxicación, cambios en la presión arterial y aumento metabólico del hígado, entre otros; y a nivel mental altera el pensamiento y el razonamiento (juicio).

Según Llano y Campuzano (1994), se presume que el origen de la palabra Chicha es indígena debido a dos hechos. Por un lado, gran cantidad de palabras chibchas empiezan con las sílabas 'chi' y 'cha', mientras que no hay muchos registros de vocablos que contengan estos prefijos en el idioma castellano; y por otro, la bebida no era conocida en España. Por lo anterior, se piensa que, al nombrar la bebida, los españoles confundieron la palabra Chicha con algún atributo de la misma.

Existen más interpretaciones de lo anterior: "[para] Ortegón [...] Chicha en idioma chibcha se forma de $c h i$ que quiere decir nuestro, nuestras, nuestra y cha que quiere decir varón, varones o machos. Por consiguiente decir Chicha es como si se dijera para nuestros varones, cosa hecha para los machos" (Llano \& Campuzano, 1994, p. 26). Llano y Campuzano interpretan lo anterior como una afirmación de que los hombres eran los únicos que bebían Chicha, pero creo que esto es errado; en lugar de ello, significa que la Chicha estaba reservada a gente "macha" o fuerte, y no que era exclusiva de los hombres. Por otro lado, el Diccionario de la Real Academia Española (2001) señala que el término 'Chicha' deviene de una voz aborigen de Panamá, Chichab, que significa "maíz”.

En Sutatenza, Macanal y Guateque se usa el maíz de harina para la elaboración de la Chicha. Este se compone, fundamentalmente, de un almidón muy blando, y por ello es susceptible a la pudrición y a los gusanos; sin embargo, esta condición propicia la buena germinabilidad de las semillas (Paliwal, Granados \& Violic, 2001). Por esto, debe mantenerse un tiempo estándar para la fermentación del grano.

La historia de la Chicha comienza con el cultivo del maíz, el cual es la base de la dieta alimentaria de la mayoría de los pueblos indígenas en Colombia. En la actualidad, no se tienen todos los indicios para saber si la bebida era de uso cotidiano o exclusivamente ritual, pero sí se sabe que "gran parte de la cosecha de maíz se debía destinar a la elaboración de un elemento fundamentalmente ritual: la Chicha de maíz" (Llano \& Campuzano, 1994, p. 22). Por ello, desde sus inicios tuvo un fuerte significado social y cultural.

La Chicha acompañaba diferentes tipos de rituales muiscas; para este grupo no había condicionamiento social alguno respecto a la cantidad 
de bebida que se podía beber, pero sí respecto a los eventos y situaciones en las que era posible hacerlo. Sin embargo, la llegada de los conquistadores españoles al altiplano cundiboyacense cambió muchas costumbres, a la vez que marcó la imposición violenta de su idioma y, en general, de su forma de organización social, cultural y política.

Estos cambios transformaron la forma y el objetivo con el que se tomaba la Chicha, en tanto era consumida constantemente por los españoles para sustituir sus vinos españoles: "los conquistadores y colonizadores hicieron uso de la bebida indígena y algunos de ellos la encontraron tan de su agrado, que después, cuando se trajeron [...] los ricos vinos de España, fueron mirados por muchos con desdén" (Bejarano, 1950, p. 31). Esta nueva forma de consumir la Chicha se expandió por todo el territorio, principalmente en Santafé de Bogotá.

Lo anterior trajo consigo consecuencias tales como el aumento del comercio de la Chicha bajo condiciones higiénicas cuestionables, problemas de orden público y comportamientos agresivos. Por ello, arzobispos, padres y demás miembros de la iglesia católica, el Rey y el Virrey (por medio del Gobernador del Nuevo Reino de Granada) $\mathrm{y}$, en general, las autoridades civiles (Llano \& Campuzano, 1994), impusieron serias restricciones en relación con su consumo. En el caso del Valle de Tenza se encuentra una declaración del sacerdote de Sutatenza en 1799 (citado por Llano \& Campuzano, 1994), en la que este pide la prohibición de la Chicha:

Los indios de los que me consta principalmente de este pueblo de Suta que desde el Domingo hasta el otro Domingo y a este paso todo el año, viven metidos en las casas de chicherías abandonando sus propias casas y los cortos reales que adquieren los gastan en la bebida con grandísimo perjuicios de sus almas, intereses de su Magestad y de las limosnas que tienen que contribuir a sus Cofradías [...] por expresiones del cura de Guateque por Don Nicolás Cuerbo y mías a promover que no se venda la Chicha. (p. 52)
La situación descrita afectó a todo el país y se generó una serie de prohibiciones sobre la producción de la Chicha. En 1658, el primer gobernante de la colonia, Pérez Manrique, impuso sanciones a sus consumidores: cerró las chicherías los días festivos (domingos) y asignó impuestos a las mismas. En épocas posteriores se mantuvo la idea de que las chicherías eran lugares de desaseo y de contagio de enfermedades, y por ello se dio inicio a una campaña que abordaba varios frentes: los medios de comunicación (véanse las figuras 1 y 2), el Ministerio de Salud e Higiene, el centro económico y la legitimación social (Llano \& Campuzano, 1994). Se creía entonces que la Chicha era la causa principal de todos los problemas sociales.

Solo hasta 1948 el Congreso Nacional aprobó la Ley 34, que "prohibía desde el primero de enero de 1949, la fabricación, venta y consumo de bebidas fermentadas que no se ajustaran a los severos requisitos prescritos alli’" (Bejarano, 1950, p. 17). Con esta Ley y sus radicales sanciones se eliminaron casi todas las chicherías del país y se sustituyó la Chicha por la cerveza, la cual iba a eximir al

[...] pueblo del embrutecimiento y permitirle al país alcanzar un desarrollo económico con el trabajo de los obreros. Se trataba de sustituir un hábito ancestral por un producto también fermentado, pero que tenía características más acordes con la civilización y modernización (Llano \& Campuzano, 1994, p. 106).

Figura 1

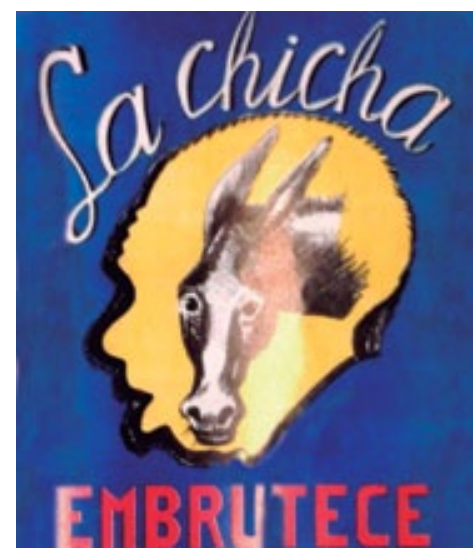

Fuente: Bejarano (1950). 
Figura 2

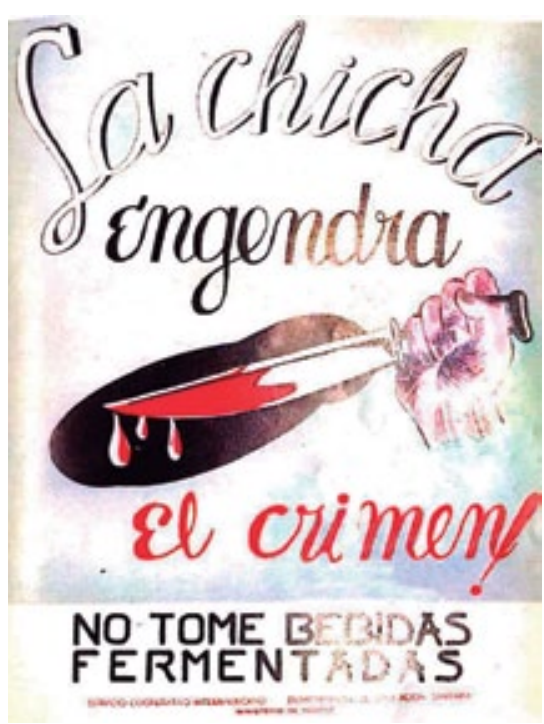

Fuente: Bejarano (1950).

De lo anterior se desprendió una campaña en los medios de comunicación sobre las propiedades nutritivas e higiénicas de la cerveza. A su turno, en Bogotá y Boyacá el consumo de Chicha bajó significativamente, evento que en la actualidad sigue siendo un hecho contundente. Cuarenta años después de la prohibición de la Chicha, la misma volvió a la escena social, aunque cabe resaltar que nunca ha desaparecido de los contextos campesinos y familiares del altiplano cundiboyacense.

En los contextos campesinos, y particularmente en el Valle de Tenza, la Chicha representa un elemento de identidad, historia, resistencia, opresión, libertad y tradición, unión y colectividad, que está siendo modificado por las actuales dinámicas sociales, culturales, políticas, económicas y educativas por las que atraviesa el país. Llano y Campuzano (1994) lo expresan en estos términos:

Hablar de Chicha es hablar de rituales, de ceremonias, de tradición, es hablar del pueblo, de los indios, hablar de la tierra, hablar del maíz, de los orígenes [...] pero también hablar de Chicha es hablar de represión, de ideología, de racismo [...] de imposiciones, es hablar de higiene, de motines del bulldozer, de la empresa capitalista. Hablar de Chicha es hablar del choque de dos culturas [...] hablar de Chicha es hablar de identidad [...] (pp. 15-16).
El caso estudiado aquí corresponde, entonces, a una identidad campesina que se ha construido alrededor de la Chicha y confiere particularidades socioculturales a la zona del Valle de Tenza.

\section{Descripción y caracterización metodológica}

Con el fin de reconocer los saberes locales en el trabajo, s,e usó un enfoque etnográfico a nivel micro. Se entiende este como "un método que procura la recopilación más completa y exacta posible de la información necesaria para reconstruir la cultura y conocer los fenómenos sociales propios de comunidades y grupos muy específicos" (Cerda, 1993, p. 82); entra en esta descripción la comunidad del Valle de Tenza, donde se tejen diferentes relaciones sociales, económicas, culturales y educativas alrededor de la Chicha. El nivel micro, a su turno, "consiste en focalizar el trabajo de campo a través de la observación e interpretación del fenómeno en una sola institución social, en una o varias situaciones sociales" (Barbolla, Benavente, López, Almagro, Perlado \& Serrano, 2010, p. 4). En este caso, está centrado en la recopilación y caracterización de los saberes en torno a la producción de Chicha en la comunidad del Valle de Tenza.

El enfoque etnográfico utiliza varios modos de recolección de la información (e. g. observación, entrevista, análisis de documentos), con el fin de "capturar el punto de vista, el sentido, las motivaciones, intenciones y expectativas que los actores otorgan a sus propias acciones sociales, proyectos personales o colectivos, y al entorno sociocultural que los rodea" (Tamayo, 2004, p. 62). El método investigativo seleccionado se utilizó basado en un tipo de investigación cualitativa, que según Pérez (citado por Sarduy, 2007, pp. 6-7) es:

Un tipo de investigación formativa que cuenta con técnicas especializadas para obtener respuesta a fondo acerca de lo que las personas piensan y sienten. Su finalidad es proporcionar una mayor comprensión acerca del significado de las acciones de los hombres, sus actividades, motivaciones, valores y significados subjetivos. 
En consecuencia, se utiliza para "estudiar los contextos estructurales y situacionales, tratando de identificar la naturaleza profunda de las realidades, su sistema de relaciones, su estructura dinámica" (Sarduy, 2007, p. 7). Con ello, se identificaron generalidades y particularidades que permitieron caracterizar el saber local y su relación con la comunidad. Además, se tuvieron en cuenta las "descripciones detalladas de situaciones, eventos, personas, interacciones y comportamientos que son observables. [el método] Incorpora lo que los participantes dicen, sus experiencias, actitudes, creencias, pensamientos y reflexiones tal como son expresadas por ellos mismos y no como uno los describe" (González \& Hernández, 2003, p. 20). Lo anterior para no omitir detalles importantes, generar interpretaciones erróneas y, con ello, resultados ambiguos en la investigación.

Este estudio se realizó en el departamento de Boyacá (véase la figura 3), en el Valle de Tenza, particularmente en los municipios de Sutatenza,
Guateque y Macanal, los cuales se encuentran entre las coordenadas esféricas $73.1^{\circ} \mathrm{W}$ a $73.6^{\circ} \mathrm{W}$ y $4.8^{\circ} \mathrm{N}$ a $5.1^{\circ} \mathrm{N}$. Es un área con tradición de desarrollo rural, y para el 2011 el 58\% de la población se ubicaba en dicho sector. Pese a esto, en comparación con épocas pretéritas se observa una pérdida de la población rural, ya que en 1993 esta representaba el 70\% (Incoder, 2012).

\section{Diseño metodológico, técnicas y procedimientos analíticos}

En consecuencia con la metodología etnográfica, se llevaron a cabo cinco fases de desarrollo (véase la figura 4) que permitieron alcanzar los objetivos planteados.

Se realizaron búsquedas bibliográficas sobre los ejes principales de este proyecto (saberes locales y Chicha), así como un primer acercamiento a la comunidad del Valle de Tenza, por medio de preguntas semiestructuradas acerca de la

Figura 3

Mapa de la zona de estudio.

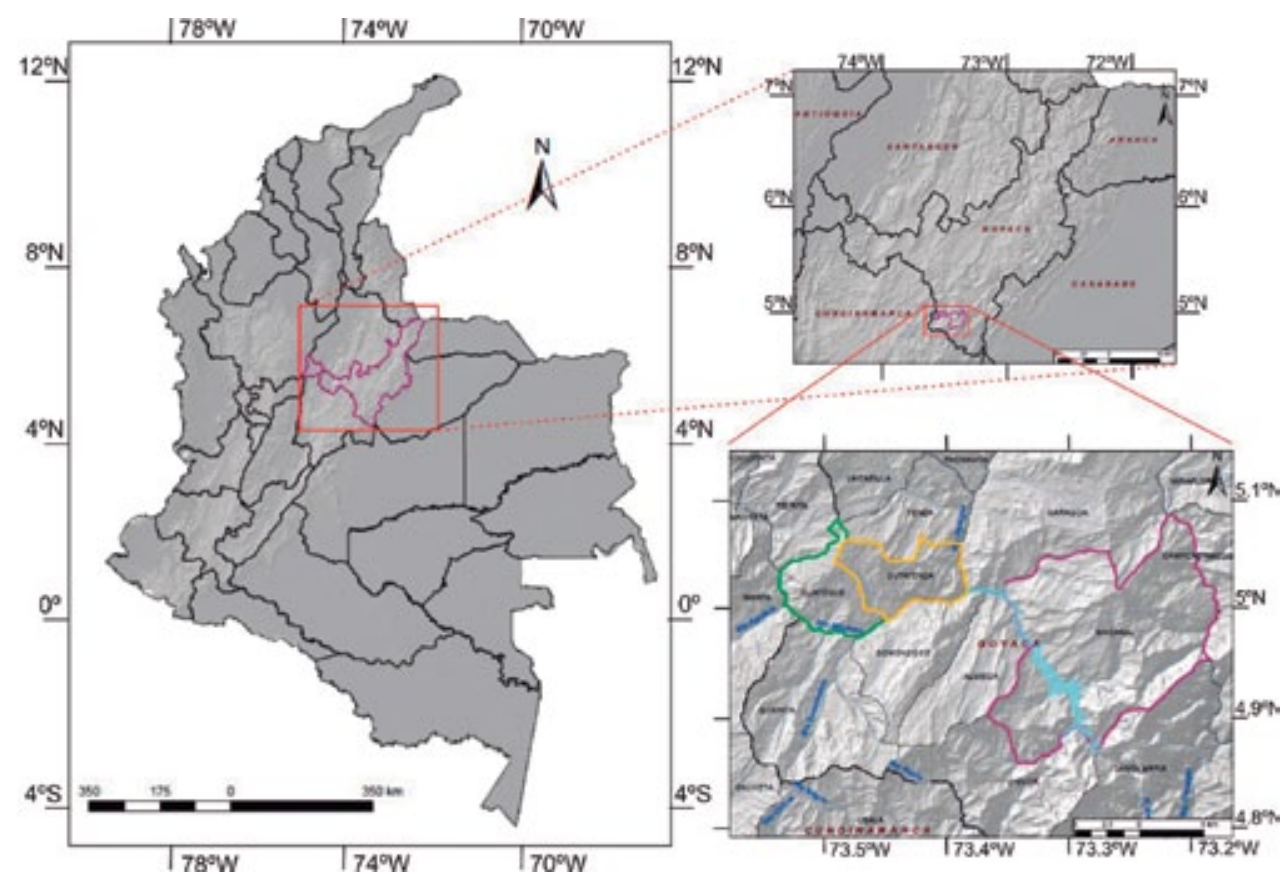

Fuente: Bedoya (2014). 
Figura 4

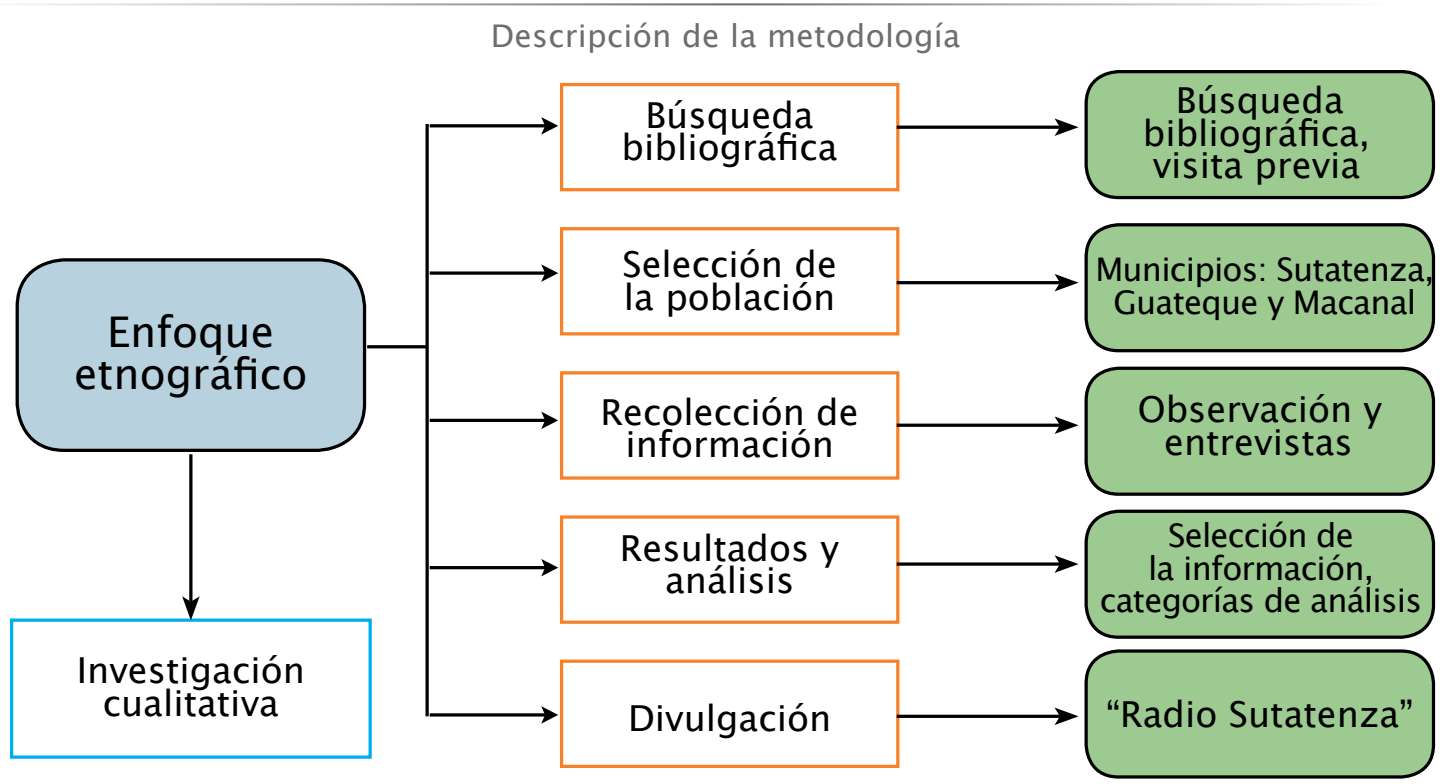

elaboración de la Chicha. Para efectos de la selección de la población, se eligieron a personas mayores y adultos de cada municipio para la realización de las entrevistas. Lo anterior debido a que las generaciones más recientes no conocen el proceso de elaboración de la Chicha.

Para el trabajo de campo se realizó un registro escrito en el cuaderno de campo, en el cual se consignaron datos importantes relacionados con las personas entrevistadas, a saber: nombre, edad, lugar de residencia, tiempo que lleva elaborando la Chicha y actividad a la que se dedica, a la vez que experiencias y anécdotas. Se realizaron 9 entrevistas semiestructuradas con preguntas abiertas respecto a la elaboración de la Chicha, a su ingesta y a su importancia en la región. Siete de ellas fueron registradas en archivos de audio y las dos restantes se registraron escrito, a solicitud de los entrevistados.

\section{Análisis de la información}

En principio, se realizó una selección y organización de la información obtenida, en busca su pertinencia con respecto a los objetivos del proyecto. Luego, se efectuó la transcripción fidedigna de siete entrevistas y una compilación digital de las dos restantes $^{3}$. Enseguida se sistematizaron las nueve entrevistas, buscando categorías que permitieran caracterizar los saberes locales. Y posteriormente, estas categorías se organizaron en una matriz de análisis. Con la información anterior se construyó una estructura general de la elaboración de la Chicha en los tres municipios. Por último, se divulgó información sobre el proyecto de investigación en la emisora Radio Sutatenza (por ser una de las más populares en Boyacá), resaltando la importancia de los saberes locales alrededor de la producción de la bebida.

\section{Caracterización de saberes locales alrededor de la producción de Chicha: resultados}

Las personas entrevistadas ( 7 mujeres y 2 hombres) están en un rango de edad entre los 47 y los 86 años. En cuanto a sus ocupaciones, se resaltan las labores en el campo, actividades comerciales in-

3 Se asignó a cada persona entrevistada un código (e. g. SA01): la primera letra representa el municipio de procedencia (en el caso de ejemplo, Sutatenza); la segunda indica la letra inicial del nombre del entrevistado; y luego se escribe el número de realización de la entrevista. 
dependientes, labores domésticas y trabajos con la Gobernación. Con respecto a la caracterización de los saberes locales de la comunidad del Valle de Tenza, se indagó y analizó la forma de producción actual de la Chicha, la cual incluye su elaboración, ingesta e importancia. De lo anterior se establecieron seis categorías de análisis a partir de la información suministrada en las nueve entrevistas, cuyo desarrollo se presenta en la tabla 1.

Tabla 1

Caracterización de saberes locales de la producción de Chicha en el Valle de Tenza

\begin{tabular}{|c|c|c|c|}
\hline $\begin{array}{l}\text { Categorías } \\
\text { de análisis }\end{array}$ & Subcategorías & Descripción & Ejemplos \\
\hline $\begin{array}{l}\text { Aspectos } \\
\text { sociolingüísticos }\end{array}$ & & $\begin{array}{l}\text { Sinonimia, semántica, } \\
\text { interpretación }\end{array}$ & $\begin{array}{l}\text { Sinonimia. 'manar' o 'cedazo': colador de fibras } \\
\text { de metal, utilizado para cernir el maíz (todos los } \\
\text { informantes). Semántica. 'chiquero': residuos } \\
\text { no deseados en la Chicha o en la miel de caña. } \\
\text { Interpretación. "Por decir media arroba de maíz salen } \\
\text { unas tres arrobas de agua" (informante SF02). }\end{array}$ \\
\hline \multirow[t]{2}{*}{$\begin{array}{l}\text { Métodos de } \\
\text { elaboración }\end{array}$} & Técnicas & $\begin{array}{l}\text { ¿Cómo se elabora? } \\
\text { ¿Qué aspectos } \\
\text { se deben tener } \\
\text { en cuenta? ¿Qué } \\
\text { técnicas específicas se } \\
\text { utilizan? }\end{array}$ & $\begin{array}{l}\text { "Se envuelve el maíz en hoja de surca, pero tiene } \\
\text { que ser en esa hoja" (MJ05). } \\
\text { "Se la echa a esa vasija, no se la echa caliente, } \\
\text { porque si se la echa caliente, ¿sabe qué pasa? Se } \\
\text { agria o se corta" (informante SA01). }\end{array}$ \\
\hline & Instrumentos & $\begin{array}{l}\text { ¿Qué materiales se } \\
\text { necesitan? } \\
\text { ¿En qué se toma la } \\
\text { Chicha? }\end{array}$ & $\begin{array}{l}\text { Totuma, ollas de aluminio y canecas plásticas, palo } \\
\text { de caña (todos los informantes). }\end{array}$ \\
\hline \multirow{3}{*}{$\begin{array}{l}\text { Consumo de } \\
\text { la Chicha }\end{array}$} & Efectos fisiológicos & $\begin{array}{l}\text { ¿Cuáles son los } \\
\text { efectos que causa la } \\
\text { Chicha en el cuerpo } \\
\text { humano? }\end{array}$ & "Eso los pone es a dormir" (informante SF02). \\
\hline & $\begin{array}{c}\text { Efectos } \\
\text { comportamentales }\end{array}$ & $\begin{array}{l}\text { ¿Cuáles son los } \\
\text { efectos de la Chicha } \\
\text { en el comportamiento } \\
\text { individual y social? }\end{array}$ & $\begin{array}{l}\text { "Antes eso, esa viejera, eso era para jartar, y se ha- } \\
\text { cían los problemas [...] porque se engarteraba [sic], } \\
\text { se emborrachaban" (informante SF02). }\end{array}$ \\
\hline & $\begin{array}{l}\text { Aspectos } \\
\text { nutricionales }\end{array}$ & $\begin{array}{l}\text { ¿La Chicha es una } \\
\text { bebida nutritiva? } \\
\text { ¿Qué la hace } \\
\text { nutritiva? }\end{array}$ & $\begin{array}{l}\text { "Pues siempre sí, porque, porque el maíz es de } \\
\text { sustancia y cuando uno quiere pues se le echa con } \\
\text { caldo de pezuña y queda más de alimento" (infor- } \\
\text { mante MZO1). } \\
\text { "Es nutritiva porque es de maíz" (informante } \\
\text { MA06). }\end{array}$ \\
\hline \multirow{2}{*}{$\begin{array}{c}\text { Prácticas } \\
\text { socioculturales }\end{array}$} & Aspectos sociales & $\begin{array}{l}\text { ¿De quién y cómo se } \\
\text { aprende? ¿Quiénes la } \\
\text { elaboran? ¿Quiénes } \\
\text { pueden tomarla? }\end{array}$ & $\begin{array}{l}\text { De la madre y con las amistades (MA06, MZ01, } \\
\text { SA01, GE01). } \\
\text { Actualmente mujeres y hombres, anteriormente solo } \\
\text { las mujeres. (Todos los informantes) }\end{array}$ \\
\hline & Aspectos culturales & $\begin{array}{l}\text { Música, coplas, } \\
\text { refranes, historias }\end{array}$ & $\begin{array}{l}\text { "Vamos compadrito a echar una jugarreta de tejo, } \\
\text { y de paso un vasito de Chicha" (informante MZ01). } \\
\text { "Usted no es na', ni Chicha ni limoná, se la pasa } \\
\text { manoseando caramba zamba su dignidad" (Jara, } \\
\text { 1971,7). }\end{array}$ \\
\hline
\end{tabular}




\begin{tabular}{|c|c|c|c|}
\hline $\begin{array}{c}\text { Usos } \\
\text { socioculturales }\end{array}$ & $\begin{array}{l}\text { Familiares, } \\
\text { religiosos y } \\
\text { laborales }\end{array}$ & $\begin{array}{c}\text { ¿En qué momentos se } \\
\text { elabora y consume la } \\
\text { Chicha, o para qué se } \\
\text { elabora? } \\
\text { ¿Por qué es } \\
\text { importante la Chicha? }\end{array}$ & $\begin{array}{l}\text { "Eso pa' noche buena y pa' San Juan, San Pedro, } \\
\text { eso hacían tamales de huecos, de maíz pelado } \\
\text { [...] y Chicha sí, cada ratico una atolladita (sic)" } \\
\text { (informante GE01). } \\
\text { "Hace como diez años en toda fiesta hacían Chicha" } \\
\text { (informante MSO4). }\end{array}$ \\
\hline Creencias & & $\begin{array}{c}\text { Ideas de las personas } \\
\text { sobre casos puntuales } \\
\text { en la elaboración e } \\
\text { ingesta de la Chicha }\end{array}$ & $\begin{array}{l}\text { "Se envuelve en hoja de surca, toca en hoja de sur- } \\
\text { ca, sino no sería Chicha" (SF02). } \\
\text { "Yo hago Chicha sola [...] porque hay gente que } \\
\text { dicen que tiene mala mirada, entonces eso le corta } \\
\text { todo y le daña" (MA06). } \\
\text { "La Chicha es sabroso pero es tomarlo [sic] en to- } \\
\text { tuma, ya en un vidrio ya no es igual" (informante } \\
\text { GE01). }\end{array}$ \\
\hline
\end{tabular}

\section{Aspectos sociolingüísticos}

En esta categoría se describen y analizan las variaciones lingüísticas que se presentan actualmente en el lenguaje de la comunidad del Valle de Tenza con respecto a la producción de Chicha. Estas variaciones se entienden como "el uso alterno de formas diferentes de decir lo mismo, se pueden encontrar prácticamente en todos los niveles de la lengua, desde el más concreto (fonético-fonológico) al más amplio (discurso, por ejemplo), pasando por la gramática y el léxico" (Moreno, 2009, p. 21). Particularmente, en este caso se analizan las variaciones lingüísticas desde el nivel léxico, siendo este "conjunto de las palabras de un idioma, o de las que pertenecen al uso de una región, a una actividad determinada, a un campo semántico dado" (Real Academia Española, 2001). De las variaciones léxicas se describen tres aspectos: sinonimia, semántica e interpretación.

Las variaciones lingüísticas en los tres aspectos descritos están determinadas por las relaciones geográficas y sociales que se establecieron en la comunidad a partir de la construcción social del conocimiento. Según Bernstein (citado por Lacasa, 1993), el desarrollo de códigos lingüísticos depende de las habilidades que los individuos desarrollen "en función de los tipos de interacción social que las personas mantienen con mayor frecuencia" ( $\mathrm{p}$. 8); esto explica el predominio de unos aspectos lingüísticos sobre otros. Para Bernstein (citado por Brigido, 2006), la base de los elementos sociolingüísticos "construye una teoría de la reproducción cultural cuya principal característica es que puede operar en varios niveles: institucional (macro), interaccional (micro) y de la conciencia del sujeto (subjetivo)" (p. 77); estos niveles pueden relacionarse y explicarse mutuamente.

Lo anterior se evidencia en los aspectos sociolingüísticos de la comunidad del Valle de Tenza, que surgen de la legitimación social (institucional o macro); de las relaciones que se establecen en una comunidad particular (micro); y de la frecuencia y uso de cada individuo (subjetivo).

\section{Métodos de elaboración}

Se concibe el método como "el conjunto de pasos, procedimientos, que se siguen para conseguir cierto objetivo. Para hacerlo se requieren de ciertas técnicas e instrumentos que permiten la aplicación fáctica o empírica de los mismos" (Uzeda, 1999, p. 7) (en este caso, utilizado conjuntamente por la comunidad para la elaboración de la Chicha). El método empleado por la comunidad en la actualidad se sintetiza en cuatro etapas, representadas en la figura 5 . 
Figura 5

Método de elaboración de la Chicha.

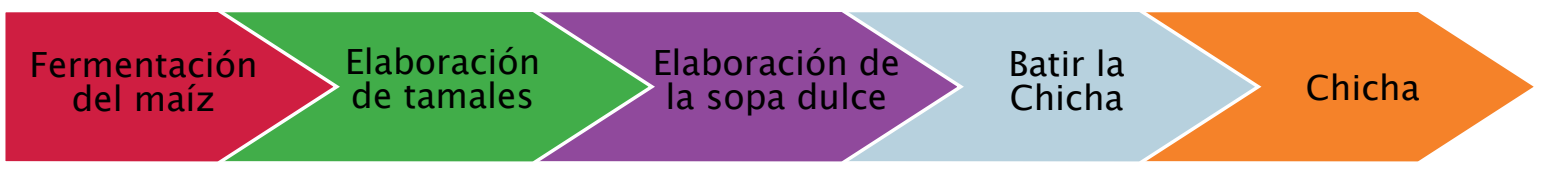

Adicionalmente, para efectos del análisis contextualizado del método, es importante anotar que este se encuentra constituido por la agrupación de "creencias (cosmos), el sistema de conocimientos (corpus) y el conjunto de prácticas productivas (praxis), lo que hace posible comprender cabalmente las relaciones que se establecen entre la interpretación [...] la imagen [...] y el uso o manejo de la naturaleza y sus procesos" (Toledo, 2005, p. 5). Esta categoría se divide en dos subcategorías: técnicas e instrumentos.

En cuanto a las técnicas, éstas en dichas generaciones pueden explicarse debido a varias cuestiones: su forma de enseñanza (analizada en la siguiente categoría); las pocas migraciones hacia otros territorios; y las particularidades geográficas de la época que no permitieron la pronta llegada del modernismo, constituyendo el lugar estudiado como un área rural en donde, por persistencia, se logró "resistir o evitar la expansión cultural y tecnológica del modelo" (Toledo, 2005 p. 3) industrial y moderno.

Las migraciones originan perdida de las costumbres, hábitos y prácticas socialmente constituidos en una comunidad, al tiempo que puede traer consigo una hibridación entre métodos que tienen diferentes orígenes socioculturales. De acuerdo con Martine, Hakkert y Guzmán (2000, p. 164), "las migraciones pueden tener efectos positivos y negativos, tanto sobre los individuos como sobre las comunidades de origen y destino". Por esto, pueden perderse ciertas técnicas y ser reemplazadas por otras. Lo anterior explica los cambios e hibridación de prácticas en el método de elaboración de la Chicha por parte de las generaciones más recientes, que tienen en promedio 45 años de edad.

En la indagación por los instrumentos utilizados antiguamente se encontraron algunas diferencias: tal es el caso de las múcuras o vasijas de barro utilizadas para batir la Chicha, el uso de vasijas de cerámica, el uso de instrumentos de madera y el empleo que hoy pervive de la ingesta de la Chicha. Esto evidencia un cambio notable en los instrumentos que se debe posiblemente a dos factores:

- La introducción de factores industriales, que se determina por los cambios en la producción de dichos instrumentos y la introducción de nuevas materias primas como el hierro, fundamentalmente introducidos por los españoles en la época de la conquista. Así, "dos esferas de la tecnología española habían sido introducidas y, al ser aceptadas, habían revolucionado tanto la producción como la distribución y habían contribuido a crear una economía colonial distinta" (Hill, 2001, p. 92) a la existente en las comunidades indígenas, legado que en la actualidad continúa.

- La naturaleza de los saberes locales, ya que estos poseen un "alto grado de apertura, flexibilidad y dinamismo, lo que los hace proclives a recibir influencias de otros sistemas de creencias, ya sean locales o globalizados" (Mora, 2008), con lo que adquieren un alto grado de hibridación en el mundo contemporáneo (Núñez, 2006; Landini, 2010, p. 23).

Antiguamente, todos los instrumentos de cocina se fabricaban con barro: las mujeres los construían con carácter ritual y utilitario de forma rudimentaria y manual. No obstante, esa costumbre se perdió poco a poco, debido a la llegada de los colonos. (Sinic, S. F.) En la actualidad, el cambio de instrumentos también se debe a la producción en masa de materiales como el plástico, que es muy accesible económicamente y puede hallarse en casi cualquier almacén. 


\section{Consumo de la Chicha}

El análisis del consumo de la Chicha se realiza a partir de tres subcategorías, a saber:

- Efectos fisiológicos: se analizan los efectos que produce la Chicha a nivel fisiológico en sus consumidores.

- Efectos comportamentales: se analizan los aspectos comportamentales de los individuos cuando ingieren la bebida.

- Aspectos nutricionales: se analizan los factores que la comunidad identifica como nutricionales en la Chicha

\section{Prácticas socioculturales}

Las prácticas socioculturales en la producción de Chicha, analizadas a partir de aspectos sociales y culturales, se definen así:

[...] las relaciones sociales que se articulan por un tiempo y un espacio a raíz de la dualidad de la estructura: el proceso por el cual "las reglas y los recursos que se aplican a la producción y reproducción de una acción social son, al mismo tiempo, los medios para la reproducción sistémica”. En otras palabras (...) son constituidas por la acción de los sujetos y, a su vez, son el medio de tal constitución (Caviglia, 2006, pp. 69-70).

Con esto, se identificaron algunas prácticas alrededor de la elaboración de la Chicha, las cuales se analizaron a partir de sus dos subcategorías:

- Aspectos sociales: se analizan las prácticas concernientes a la transmisión de saberes para la elaboración de la Chicha. ¿De quién y cómo se aprende la elaboración de la Chicha? ¿Quiénes la elaboran? ¿Quiénes pueden tomarla?

- Aspectos culturales: se describen algunos elementos culturales relacionados con la Chicha -bailes, canciones, coplas, poemas, historias o experiencias, entre otros-, construidos o escuchados por la comunidad cuando se consume la bebida.

\section{Usos socioculturales}

En esta categoría se abordan los usos actuales de la Chicha en tres eventos importantes, a saber, familiares y sociales, religiosos y "para el trabajo". Para ello se elaboraron las siguientes preguntas (además de tocar el tema su prohibición en el Valle de Tenza): ¿en qué momentos se produce y se consume la Chicha, o para qué se elabora? ¿Por qué es importante la Chicha?

\section{Creencias}

En esta categoría se analizan las creencias que los habitantes construyen alrededor de la producción de la Chicha en la región estudiada. En este caso, las creencias de los habitantes están relacionadas con los instrumentos o utensilios que se emplean para el consumo o elaboración de la Chicha, como la "totuma"; sobre las técnicas empleadas, como el uso de la hoja de surca; sobre las prácticas alrededor de su preparación, como la cantidad de personas que pueden elaborar la bebida o el estado de ánimo que deben tener; y sobre la ingesta adecuada de la bebida, entre otras, que consolidan una serie de creencias alrededor de producción de Chicha en el Valle de Tenza. La comunicación oral de las creencias fomenta diferentes interpretaciones y, "de esta manera, puede explicarse la persistencia de ciertas concepciones que, si bien tiene sentido para el autor que las sostiene, carecen de fundamento científico y de unidad práctica" (Landini, 2010, p. 24).

Las creencias son "pensamientos no evaluativos referentes a las características de los "objetos" de nuestro mundo" (Kimble et al., 2002, p. 136). Estas ideas surgen a partir de la experiencia afirmando hechos observables, que en algunas situaciones carecen de experimentación, comprobación y análisis, con lo que se llega a interpretaciones superficiales de los sucesos. Lo anterior puede explicarse, según Landini (2010), porque "un nuevo conocimiento no necesita ser verdadero para que se consolide, solo es necesario que una vez incorporado permita interpretar las experiencias" (p. 33). Esto resulta en la aceptación de dicho conocimiento por parte de la comunidad y su integración al saber local. 


\section{Conclusiones}

La categorización de los saberes locales de los habitantes del Valle de Tenza en torno a la elaboración, ingesta e importancia de la Chicha produjo seis categorías de análisis: 1) aspectos sociolingüísticos en las variaciones léxicas de sinonimia, sintaxis e interpretación; 2) métodos de elaboración, con técnicas e instrumentos; 3) consumo de la Chicha, analizado a nivel fisiológico y comportamental; 4) prácticas socioculturales, denotando las aprendidas a nivel familiar; y 5), usos socioculturales relacionados con eventos familiares, religiosos y laborales, y creencias de la comunidad en la elaboración de la bebida. Esto permitió establecer los aspectos generales que caracterizan el saber local alrededor de la Chicha.

El análisis permite considerar que los saberes locales de los procesos de elaboración en el Valle de Tenza han sufrido un proceso de hibridación constante (véase diagrama 3). Es decir, se han consolidado a partir de la mezcla e integración de diversos saberes que constituyen actualmente el saber local de los habitantes.

Figura 6

Hibridación de saberes locales

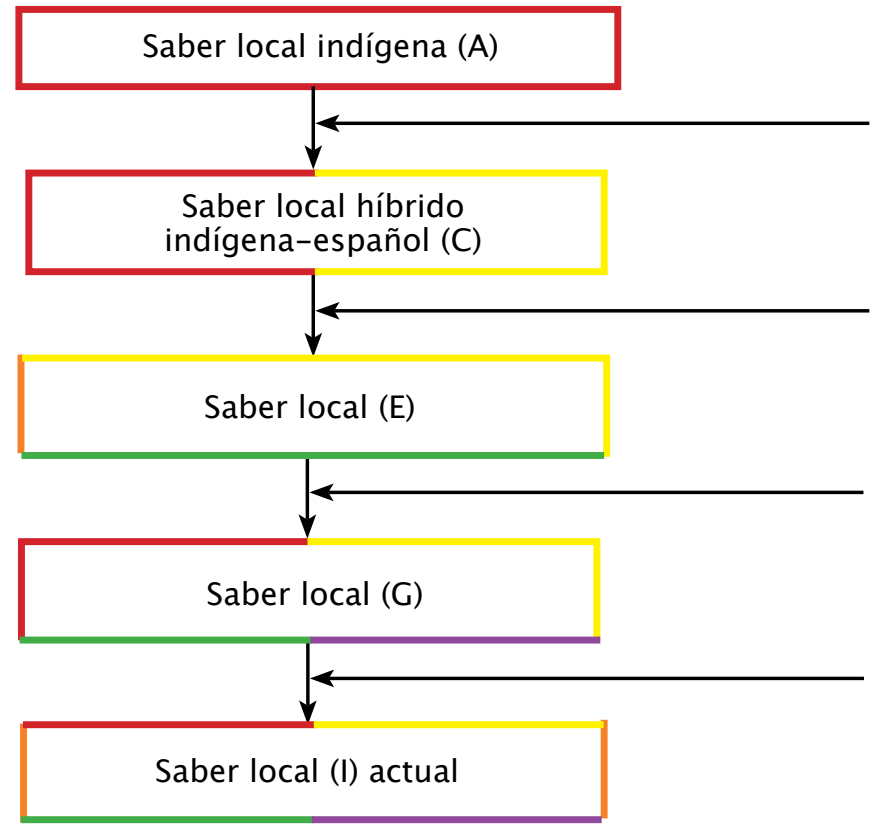

Saber de los españoles (B) durante la conquista (hacia 1538)

En principio, los indígenas construyeron saberes locales con respecto a la Chicha, generados a partir de observación, experimentación (ensayo-error), creencias espirituales y necesidades particulares. Estos "representan un conocimiento que, aunque no codificado, resuelve los problemas de la vida práctica de los miembros de la unidad social" (Torres, 2011,p. 15).Esto produjo una construcción colectiva, reflejo de las relaciones con el territorio, con los otros miembros de la comunidad y con los seres vivos a través de múltiples experiencias que permiten diversos aprendizajes. En consecuencia, se consolidaron saberes locales propios de las comunidades indígenas.

No obstante, dichos saberes se vieron alterados por la intromisión de los saberes españoles introducidos durante la conquista, suceso que también alteró otras relaciones socioculturales. En principio, la lengua muisca fue sustituida por el español, lo cual trajo como consecuencia la introducción (híbrida) de algunas palabras muiscas al español y viceversa, de tal forma que "el contacto lingüístico entre el muisca y el español produjo prestamos 
léxicos en ambas direcciones" (Giraldo, 2013, p. 79). Tal característica se muestra aún en la actualidad en diversas comunidades, en las que "algunos trabajos han puesto de evidencia la influencia léxica muisca en el español de Colombia, principalmente en el dialecto cundiboyacense" (Giraldo, 2011, p. 10), razón por la que se identifican algunos de ellos en la comunidad del Valle de Tenza.

En cuanto a la elaboración de la Chicha, los españoles también introdujeron algunos de sus saberes: "pretendieron modificar la preparación del "caoin", suprimiendo la masticación y reemplazándola por la molienda” (Bejarano, 1950, p. 22). Además, introdujeron varios instrumentos hechos de hierro y cobre y algunas plantas, "pues la Chicha de los aborígenes fue diferente a la [...] fabricada después por los colonos españoles cuando introdujeron a estos países la caña de azúcar; con ella procuraron mejorarla, modificando profundamente el método de su preparación" (Bejarano, 1950, p. 23). Al igual que en el caso anterior, esta situación estableció un híbrido entre ambos saberes.

Adicionalmente incorporaron el concepto de "limpieza", como lo menciona Simón (citado por Restrepo, 2014): "las españolas han hallado otros modos de hacerla más limpia y más curiosa y regalada" (p. 26), aludiendo a que los españoles intentaban implementar sus técnicas en la elaboración de los alimentos porque, a su criterio, las de los indígenas eran menos limpias.

Posteriormente, los procesos de cambio que se dieron en Colombia en el siglo XIX, como la industrialización y modernización del país, dieron origen a diversas variaciones socioculturales; entre ellas se encuentran las inmigraciones, que produjeron un aumento en la densidad poblacional de Bogotá y un abandono del campo, suceso que provocó problemas de salud pública e higiene (Llano \& Campuzano, 1994). A raíz de lo anterior, en años posteriores se hizo necesario establecer cátedras y Ministerios de Salud e Higiene para contrarrestar dichas afecciones sociales, por lo cual se utilizaron diversos medios para educar al pueblo en prácticas higiénicas.
Esto generó un cambio en algunas prácticas como la del hervir el agua, en la elaboración de la Chicha: "En ese sentido, se observa que el conocimiento científico, así como las prácticas asociadas a él, terminan anclándose en el conjunto de saberes del sentido común de los sujetos, luego del proceso de reconstrucción y reorganización" (Landini, 2010, p. 35).

Actualmente, las personas hierven el agua o utilizan la del filtro, se lavan las manos y limpian los utensilios, como lo señalan algunos entrevistados: "bueno primero que todo se, se hierve en un poco de miel en el agua del filtro" (ML02); "porque toca con la mano, se lava uno muy bien las manos y se pone a trabajar" (MA06); "esa vasija, bien lavada, bien organizada $[. .$.$] cocinados los ponemos en$ una vasija limpia" (SA01).

Años más tarde, la llegada del plástico trajo consigo otro cambio, en tanto que los utensilios de barro fueron reemplazados por otros fabricados con este polímero, los cuales se emplean en la actualidad. Sin embargo, y aun con la hibridación de saberes, se evidencia "una resistencia a las modificaciones [...] los alimentos y las bebidas son expresiones de larga duración en la historia de la cultura con manifestaciones de lentitud en los cambios" (Vargas, citado por Restrepo, 2014, p. 22). Esto se refleja en la Chicha, pues la estructura principal permanece intacta, según lo mencionado por Bejarano (1950):

Se muele ligeramente, en una piedra, cinco almudes de maíz tierno, amarillo, arenoso [...] se pone en maceración en una vasija de barro [...] y en los ocho primeros días se remoja con aguamiel. Después de quince días [...] se muele hasta que quede una masa fina llamada masato, que se envuelve en hojas de payaca (primun pataca-Sandino), formando bollos, que se ponen a cocer en una grande olla de barro... se deja a un fuego suave por veinticuatro horas. Después se deja enfriar el masato por tres horas y se soba en una artesa hasta que quede igual a una masa fina. A esta se le mezcla miel de caña de azúcar [...] se coloca en una múcura [...] y se mezcla con una y media totuma [...] de miel de caña, en una olla de barro la que se llena de agua. Las ollas se 
colocan en una barbacoa (mesa de cañas), cubiertas con mucho helecho y en sitio abrigado. A los seis días de fermentación, la Chicha está para tomarse en los climas fríos (pp. 42-43).

Con respecto a la antigua elaboración, el proceso en la actualidad se ha modificado en algunos elementos, técnicas, usos y creencias, como las evidenciadas en las categorías analizadas.

De lo anterior se concluye que el saber local actual respecto a la Chicha es una hibridación de varios saberes, configurada durante más de doscientos años de historia y con diferentes actores y generaciones. Los términos, los instrumentos,

\section{Referencias}

Barbolla, C., Benavente, N., López, T., Almagro, C., Perlado, L., \& Serrano, C. (2010). Investigación etnográfica, métodos de investigación educativa. Ed. Especial, Javier Murillo y Chyntia Martínez. Recuperado de http:// www.uam.es/personal_pdi/stmaria/jmurillo/ InvestigacionEE/Presentaciones/Curso_10/I_ Etnografica_Trabajo.pdf

Bejarano, J. (1950). La derrota de un vicio: Origen $e$ historia de la Chicha. Bogotá, Colombia: Editorial Iqueima.

Brigido, A. (2006). Sociología de la educación: temas y perspectivas fundamentales. Argentina: Editorial Brujas.

Caviglia, M. (2006). Dictadura, vida cotidiana y clases medias: una sociedad fracturada. Buenos Aires, Argentina: Prometeo Libros.

Cerda, H. (1993). Los elementos de la investigación, como reconocerlos, disenarlos y construirlos. Quito: Editorial el Búho, Abya Yala. Recuperado de http://es.scribd.com/doc/52701260/ Cerda-Hugo-Elementos-de-la-investigacion. las prácticas y la elaboración dan cuenta de este proceso de hibridación que ha enriquecido la producción de la bebida, debido a que esta es uno de los referentes centrales en las prácticas sociales y culturales de comunidades campesinas como la estudiada. La bebida acompaña los rituales y celebraciones más importantes de la colectividad. Sobre ella se han conformado creencias particulares que le dan sentido; se han establecido códigos sociolingüísticos propios; se ha definido un método específico de elaboración; y se han identificado sus efectos. En último término, estos elementos caracterizan las relaciones sociales de los campesinos y contribuyen al fortalecimiento de su identidad y de sus saberes locales.
Real Academia Española (2001). Chicha, Léxico, instrumento. Recuperado de: http://lema. rae.es/drae/?val=Chicha

Giraldo, A. (2011). Lengua e identidad: el caso de la lengua música en Colombia. Collaborators of Contenders Norwegian Research, Business and Politics in Latin America. Simposio llevado a cabo en Bergen, Noruega. Recuperado de http://www.lenguasdecolombia.gov.co/revista/sites/lenguasdecolombia.gov.co.revista/ files/articulo2_0.pdf

Giraldo, A. (2013). Hispanismos en el muisca. Vocabulario de la lengua chibcha o mosca, manuscrito 11/2922. Forma y función, 26(2), 77-97.

González, J. \& Hernández, Z. (2003).Paradigmas emergentes y métodos de investigación en el campo de la orientación.

Hill, R. (2001). Los Kaqchikeles de la época colonial: adaptaciones de los Mayas del altiplano al gobierno español, 1600-1700. Guatemala: Editorial Cholsamaj. 
Instituto Colombiano de Desarrollo Rural(2012). Caracterización socio-demográfica del área de desarrollo rural de Valle de Tenza. Recuperado de http://www.incoder.gov.co/documentos/Estrategia\%20de\%20Desarrollo\%20 Rural/Pertiles\%20Territoriales/ADR VALLE\%20DE\%20TENZA115/Perfil\%20 Territorial/CARACTERIZACION\%20 SOCIODEMOGRAFICA\%20VALLE\%20 DE\%20TENZA.pdf

Kimble, C., Hirt, E., Díaz-Loving, R., Hosch, H., Lucker, W. \& Zárate, M. (2002). Psicología social de las Américas. México: Pearson Educación.

Landini, F. (2010). La dinámica de los saberes locales y el proceso de localización del saber científico. Algunos aportes desde un estudio de caso. Cuadernos de Desarrollo Rural 7(65), 21-43.

Lacasa, P. (1993). La construcción social del conocimiento: desarrollo y conflicto sociocognitivo, una entrevista a Willem Doise. Infancia y Aprendizaje, 61, 5-28.

Llano, M. \& Campuzano, M. (1994). La Chicha, una bebida fermentada a través de la historia. Colombia: Cerec.

Martine, G., Hakkert, R. \& Guzmán, J. (Septiembre, 2000). Aspectos 116 sociales de la migración internacional: consideraciones preliminares. Migración Internacional en las Américas. Simposio llevado a cabo por la Comisión Económica para América Latina y el Caribe (CEPAL), (CELADE), (OIM), San José de Costa Rica.

Moreno, F. (2009). Principios de sociolingüistica y sociologia del lenguaje. España: Ariel .

Núñez, J. (2006). Formación docente y saberes locales: una mirada desde la ruralidad. Venezuela. Revista electrónica Educare, 2(1), 25-32. Recuperado de: http://www.revistas.una.ac.cr/ index.php/EDUCARE/article/view/1373
Paliwal, R., Granados, G., Renée, H. \& Violic, A. (2001). El maiz de los trópicos, mejoramiento $y$ producción. Roma: FAO, Organización de las Naciones Unidas para la Agricultura y la Alimentación.

Restrepo, C. (2014). La alimentación en la vida cotidiana del Colegio Mayor de Nuestra Señora del Rosario, 1653-1773, 1776-1900. Bogotá: Ministerio de Cultura.

Sarduy, Y. (2007). El análisis de la información y las investigaciones cuantitativa y cualitativa. Revista cubana de salud pública, 33, 12.

Sistema Nacional de Información Cultural (S. F). Colombia cultural, 119 artesanías Amazonas. Ministerio de Cultura. Recuperado de http:// www.sinic.gov.co/SINIC/ColombiaCultural/ ColCulturalBusca.aspx ?AREID $=3 \&$ SECID $=$ $8 \& \operatorname{IdDep}=91 \&$ COLTEM $=217$.

Steinkraus, K. (Ed). (1995). Handbook of indigenous fermented foods. Estados Unidos: Marcel Dekker, INC.

Tamayo, M. (2004). El proceso de la investigación cientifica. México: Limusa, Grupo Noriega Editores.

Torres, F. (2011). Investigación-Acción Participativa en saberes locales en agricultura. Ministerio federal de Cooperación económica y desarrollo. Programa AACC. Recuperado de: http://www.infoandina.org/sites/default/files/publication/files/investigacion accion_participativa_en_saberes_locales.pdf.

Toledo, V. (2005). La memoria tradicional: la importancia agroecológica de los saberes locales. LEISA revista de agroecología, 20(4), 16-19. Recuperado de http://www.leisa-al.org/web/ revista-leisa/86-vol20n4.html

Uzeda, A. (1999). El saber (local) de los cultivadores de papa: una querencia en las alturas. UMSS-Universidad Mayor de San Simón, Facultad de Ciencias Económicas. Recuperado de http://biblioteca.clacso.edu.ar/Bolivia/ iese- umss/20130218012251/vasquez.pdf. 